\title{
Tide Gauges: From Single Hazard to Multi-Hazard Warning Systems
}

By Angela Hibbert, Liz Bradshaw, Jeff Pugh, Simon Williams, and Philip Woodworth

As the name suggests, tide gauges were originally devised for the singular purpose of monitoring tidal fluctuations in sea level in order to aid safe navigation and port operations. Early tide gauges, such as that used by the famous dockmaster William Hutchinson at Liverpool in the late eighteenth century, consisted of little more than graduated markers on sea walls or posts, against which the sea surface could be measured by eye (Figure 1). These were used to record and then forecast the times and heights of high and low water each day; printed in local tide tables, they provided rudimentary information on variations in the tide.

Within 50 years, automatic (or "self-registering") stilling well and float systems were developed, consisting of a float housed in a large vertical tube, with an opening to the sea. The float would rise and fall with the sea surface and, by means of a pen connected to the float via a pulley system, its movements were captured on a paper chart fixed to a clock-driven chart recorder. This, for the first time, produced a continuous sea level trace, allowing other phenomena such as seiches, storm surges, and tsunamis to be clearly identified. Very high frequency variations in sea level, such as wave action, remained unsampled due to the damping effect of the stilling wells.

Through continued operation of these gauges over many decades, evidence of longer-term hazards emerged from their records, such as climate change-related sea level rise (SLR), a topic that is now considered in the

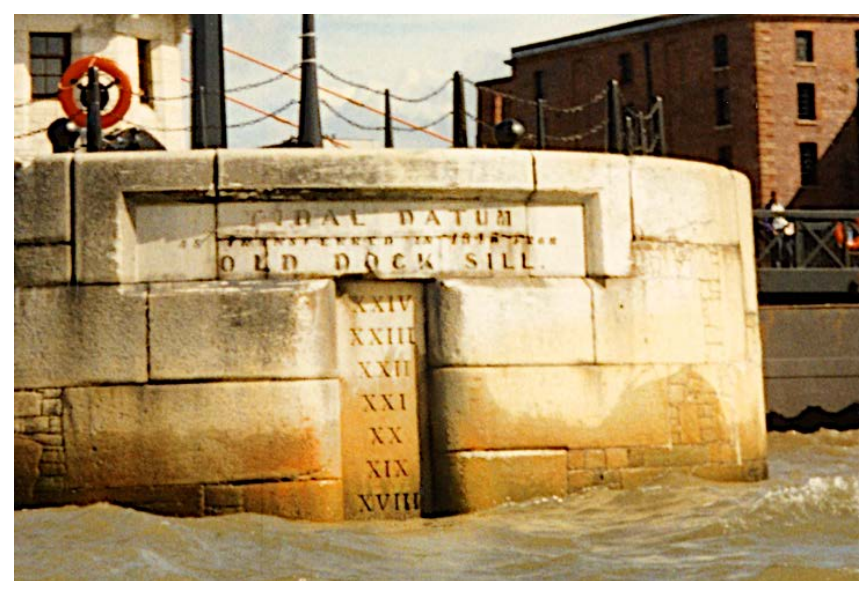

FIGURE 1. An example of a visual "tide gauge" engraved on a harbor wall, showing tide level markings at the entrance to Canning Half-Tide Dock, Liverpool, relative to the Old Dock Sill datum, a reference datum defined around 1715 in terms of the sill of Liverpool's first dock. Photo credit: Philip Woodworth, National Oceanography Centre important regular assessments of the Intergovernmental Panel on Climate Change (IPCC). Over the past few decades, a transition to radar, acoustic, or pressure-based tide gauges, together with advances in data-logging capacity, has enabled high frequency sampling $(\sim 1 \mathrm{~Hz})$ that is also necessary for monitoring wave action; in addition, the co-location of Global Navigation Satellite System (GNSS) receivers with tide gauges has allowed scientists to infer the contributions of vertical land motion to rates of SLR. As a result, modern tide gauge networks are better equipped to monitor a wide range of sea level phenomena and are, therefore, viewed as multi-hazard warning systems.

Of course, robust warning systems demand a comprehensive network of monitoring stations together with coordinated and timely notifications of impending hazards. Sadly, the impetus for such developments has often been provided by natural disasters. The UK Tide Gauge Network (UKTGN), for example, was formed primarily for the purposes of storm surge monitoring and forecasting following the 1953 North Sea storm surge that led to the loss of $\sim 2,400$ lives. More recently, the devastating Sumatran tsunami of 2004 galvanized international cooperation, via the Intergovernmental Oceanographic Commission (IOC), to establish and augment hazard warning tide gauge networks in high-risk areas such as the Indian Ocean and the Caribbean and Mediterranean Seas and to upgrade to modern near-real-time data transmission methods such as the Inmarsat Broadband Global Area Network (BGAN) system.

The BGAN system was originally custom built to retrieve data from the remote stations of the UK's South Atlantic Tide Gauge Network, which was established with the primary scientific aim of monitoring variability in circumpolar ocean transport in the South Atlantic and Southern Ocean. However, the network is now also the primary means of tsunami detection in the remote Southwest Atlantic (Figure 2), where there is presently no coordinated international early warning system. This brings us to an important point about the role of tide gauges in hazard warning: while some gauges are embedded solely as operational tools alongside numerical models within dedicated tsunami and/or storm surge early warning systems, they can never truly achieve multi-hazard status without some scientific evaluation after data collection. Design levels for sea defenses required by planners and civil engineers can only be derived thorough risk assessments, using qualitycontrolled observational data to estimate the combined 

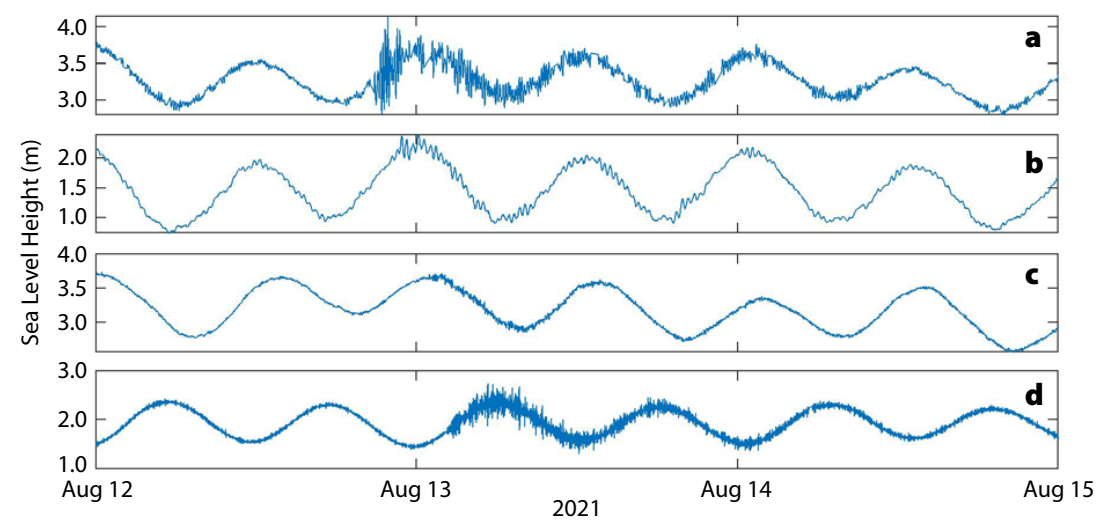

FIGURE 2. This tide gauge time series tracks sea level height $(m)$ for the South Atlantic Tide Gauge Network locations: (a) South Georgia, (b) Stanley (Falkland Islands), (c) Vernadsky, and (d) St. Helena. It shows a tsunami generated following a magnitude 8.1 earthquake in the South Sandwich Islands on August 12, 2021. Note that the difference in arrival times is consistent with the distances the tsunami must have traveled.

probabilities of coinciding hazards such as storm surges, extreme wave conditions, and high tides, as well as rates of SLR, which may exacerbate such risks even further.

The major impediment to implementation is financialtide gauge systems can be expensive to install and maintain, particularly in hurricane-prone or remote regions. The Caribbean network (coordinated by the IOC's Intergovernmental Coordination Group/Caribe-Early Warning System), for instance, is tasked with maintaining the operational status of about 80 monitoring stations. However, given that as many as 30\% of these stations may be offline at any given time for various reasons, resources must always be dedicated to their repair. In addition, there is limited financial capacity regionally for quality control and data analysis for monitoring, understanding, and predicting many phenomena, such as tides or SLR. Even longestablished networks like the UKTGN have faced funding pressures over the last decade, resulting in increasingly poor-quality observations that are of limited use beyond flood forecasting. These financial challenges can render tide gauge data useless to local communities, scientists, planning authorities, and policymakers alike.

Thus, recent technology developments have focused on developing low-cost resilient tide gauge systems with extended functionality to observe additional hazards, increasing stakeholder interest (and, ideally, funding potential). Tide gauges designed for developing economies have adopted solar- or wind-powered technology and publicly available geostationary satellite communications systems in order to minimize utility costs to local operators and promote system longevity. A novel application of GNSS systems is also being developed to monitor the sea surface from buildings and higher ground in hurricane prone areas, thereby minimizing the risk of damage that a conventional tide gauge might suffer. This technique, known as GNSS Interferometric Reflectometry (GNSS-IR), exploits

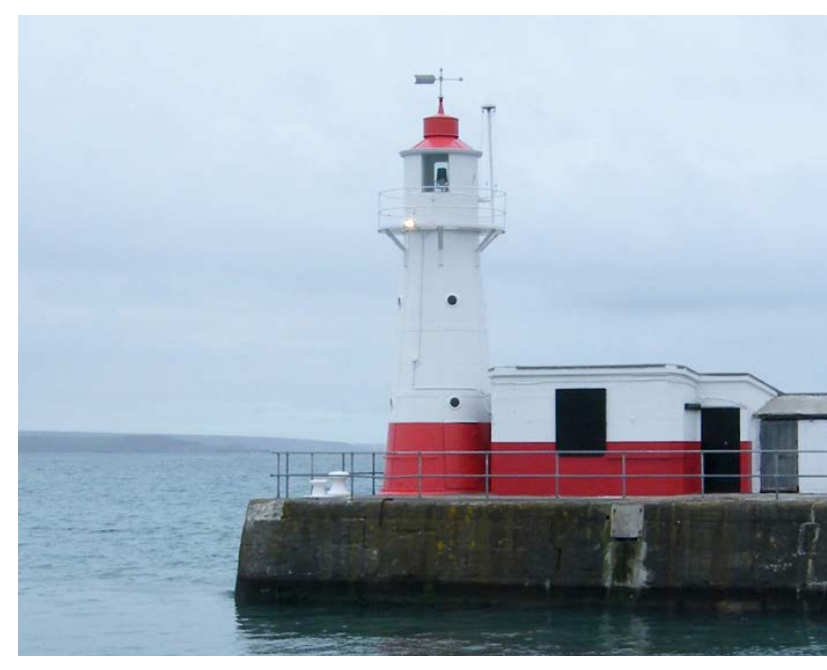

FIGURE 3. The Newlyn Tidal Observatory is one of the sites for the National Oceanography Centre's UK Tide Gauge prototype project designed to trial the use of Global Navigation Satellite System Interferometric Reflectometry (GNSS-IR) for sea level monitoring. The antenna used for these measurements can be seen on a pole to the right of the lighthouse window. Photograph credit: Les Bradley

a periodic variation in the signal-to-noise ratio between a direct GNSS signal and one that is reflected from a relatively flat surface (such as the sea), allowing the elevation of the flat surface (i.e., sea level height) to be inferred. At present, GNSS-IR does not offer the high-frequency sampling or low latency communications needed for tsunami monitoring, but it lends itself to environments that are unsuitable for conventional tide gauge instrumentation and where the risk of tsunamis is lower. GNSS-IR is being adopted in several innovative European tide gauge networks, for example, those planned by the Horizon 2020 EuroSea project and by the National Oceanography Centre's UK Tide Gauge Prototype project (Figure 3).

For these installations, the role of GNSS-IR extends beyond measuring sea level to monitoring significant wave height across extensive areas of bays and harbors. Other recent trials have shown that GNSS-IR can be adapted to monitor changes in beach profiles, soil moisture, sea ice, permafrost, and vegetation. This implies that a GNSSequipped tide gauge system of the future might not only be capable of detecting multiple sea level hazards but also could be used to monitor their impacts on the surrounding environment, which would be a valuable tool indeed. Given that GNSS receivers have also been shown capable of detecting earthquakes in as little as 15 seconds after they occur, these instruments have the potential to revolutionize the use of tide gauges in multi-hazard warning systems. 


\section{AUTHORS}

Angela Hibbert (anhi@noc.ac.uk), Jeff Pugh, Simon Williams, and

Philip Woodworth, National Oceanography Centre, Liverpool, UK. Liz Bradshaw, National Oceanography Centre and British Oceanographic Data Centre,

Liverpool, UK.

\section{ARTICLE CITATION}

Hibbert, A., L. Bradshaw, J. Pugh, S. Williams, and P. Woodworth. 2021. Tide gauges: From single hazard to multi-hazard warning systems. Pp. $82-83$ in Frontiers in Ocean Observing: Documenting Ecosystems, Understanding Environmental Changes, Forecasting Hazards. E.S. Kappel, S.K. Juniper, S. Seeyave, E. Smith, and M. Visbeck, eds, A Supplement to Oceanography 34(4), https://doi.org/10.5670/oceanog.2021. supplement.02-29.

\section{COPYRIGHT \& USAGE}

This is an open access article made available under the terms of the Creative Commons Attribution 4.0 International License (https://creativecommons.org/ licenses/by/4.0/), which permits use, sharing, adaptation, distribution, and reproduction in any medium or format as long as users cite the materials appropriately, provide a link to the Creative Commons license, and indicate the changes that were made to the original content. 